\title{
SGLT-2 inhibitors and their potential in the treatment of diabetes
}

This article was published in the following Dove Press journal:

Diabetes, Metabolic Syndrome and Obesity:Targets and Therapy

26 November 2013

Number of times this article has been viewed

\section{Rebecca F Rosenwasser' \\ Senan Sultan ${ }^{2}$ \\ David Sutton ${ }^{2}$ \\ Rushab Choksi' \\ Benjamin J Epstein ${ }^{3}$}

'East Coast Institute for Research, Jacksonville, FL, USA; ${ }^{2}$ Northeast Florida Endocrine and Diabetes Associates, Jacksonville, FL, USA; ${ }^{3}$ Department of Pharmacotherapy and Translational Research, University of Florida College of Pharmacy, Gainesville, FL, USA
Correspondence: Rebecca F Rosenwasser East Coast Institute for Research, 3550 University Blvd, Suite \#I0I, Jacksonville, FL 32216, USA

$\mathrm{Tel}+\mathrm{I} 8132205217$

Fax +| 904854 I355

Email rebecca.rosenwasser@ecirmed.com
Abstract: Diabetes remains a burgeoning global problem, necessitating ongoing efforts on the part of pharmaceutical and device manufacturers, patients, and society to curb the frightening trends in morbidity and mortality attributable to the malady. Since 1835 when phlorizin was discovered, sodium glucose co-transporter 2 (SGLT-2) inhibitors have rested tantalizingly on the horizon, promising a more physiological approach to glucose control. These agents lower glucose by enhancing its excretion by blocking reabsorption in the renal tubules, thus eliminating glucose from the body along with the molecules' attendant effects on caloric balance, plasma osmolality, and lipids. Consequently, SGLT-2 inhibitors improve glucose control to an extent comparable to other hypoglycemic agents while simultaneously reducing body weight, blood pressure, and cholesterol - an admirable portfolio. One agent, canagliflozin, has recently been approved by the US Food and Drug Administration (FDA) and two other agents have progressed through Phase III trials, including dapagliflozin and empagliflozin. Collectively, when used as monotherapy, these agents have demonstrated reductions in hemoglobin $\mathrm{A}_{1 \mathrm{c}}\left(\mathrm{HbA}_{1 \mathrm{c}}\right)$, body weight, and blood pressure of $-0.34 \%$ to $-1.03 \%,-2.0$ to $-3.4 \mathrm{~kg}$, and -1.7 to $-6.4 \mathrm{mmHg} /-0.3$ to $-2.6 \mathrm{mmHg}$ (systolic blood pressure/diastolic blood pressure), respectively. SGLT-2 inhibitors have been well tolerated, with hypoglycemia $(0.9 \%$ to $4.3 \%)$ occurring infrequently in clinical trials. Safety signals related to breast and bladder cancer have arisen with dapagliflozin, though these are unsubstantiated and likely ascribed to the presence of preexisting cancer. As these agents emerge, clinicians should embrace the addition to the formulary for treating type 2 diabetes, but must also weight the risk-benefit of this new class in deciding which patient types are most likely to benefit from their novel mechanism of action.

Keywords: diabetes, sodium-glucose transporter 2, canagliflozin, dapagliflozin, empagliflozin

\section{Introduction}

Diabetes mellitus (DM) impacts more than 25 million people in the US and continues to escalate in numbers due to obesity, decrease in leisurely physical activity, and an aging population. ${ }^{1-3}$ DM is not only the leading cause of kidney failure, nontraumatic lower-limb amputations, and blindness among adults in the US, but is also a major cause of cardiovascular (CV) disease and stroke, and is the seventh leading cause of death in the US. ${ }^{1-3}$ Although diabetes often cannot be prevented, its complications can be minimized through appropriate glycemic control; for every one percentage point drop in $\mathrm{A}_{1 \mathrm{c}}$ (eg, from $8.0 \%$ to $7.0 \%$ ) there is a $40 \%$ reduction in the risk of microvascular complications (eg, retinopathy, nephropathy, and neuropathy). ${ }^{1,3}$ However, despite documented benefits of glycemic control, about half of the patients 
with DM do not attain the American Diabetes Associated (ADA) recommended target $\mathrm{A}_{1 \mathrm{c}}$ of $<7.0 \%$ and even less meet the American Association of Clinical Endocrinologists (AACE) goal of $\mathrm{A}_{1 \mathrm{c}}<6.5 \%{ }^{4,5}$ Lifestyle interventions remain a crucial aspect of managing DM; however, most patients will not reach their goal with these interventions alone and will require pharmacological therapies. ${ }^{4}$ While several classes of medications have been proven safe and effective, most patients do not experience a durable reduction in their blood glucose and require insulin and/or experience microvascular and macrovascular complications. Therefore, new classes of medications on the horizon are aimed at attacking DM in new ways and targeting the conditions that coexist with DM, such as obesity and hypertension, in order to reduce the risk for end organ damage.

Our understanding of the pathophysiology of diabetes has progressed over time with recent research identifying eight pathophysiological defects, termed the "ominous octet," involved in the development of diabetes. ${ }^{4}$ Included in these eight defects are the kidneys and associated renal glucose homeostasis, which up until now, have been neglected from novel DM treatment modalities (Figure 1). ${ }^{4,6}$ With this advanced knowledge of the kidney's influence on glycemic control, a new approach for innovative pharmaceutical agents is improving glycemic control by promoting glucosuria. ${ }^{6}$ The objective of this review is to discuss the role of the kidney in glucose homeostasis and evaluate the efficacy, safety, and clinical importance of a novel drug class, the sodium glucose co-transporter 2 (SGLT2) inhibitors.

\section{The role of kidneys in glucose homeostasis}

Healthy individuals have the ability to maintain plasma glucose concentrations within a normal range of 3.9-8.9 mmol/L, despite their diet, due to a closely regulated homeostatic system balancing glucose production, reabsorption,

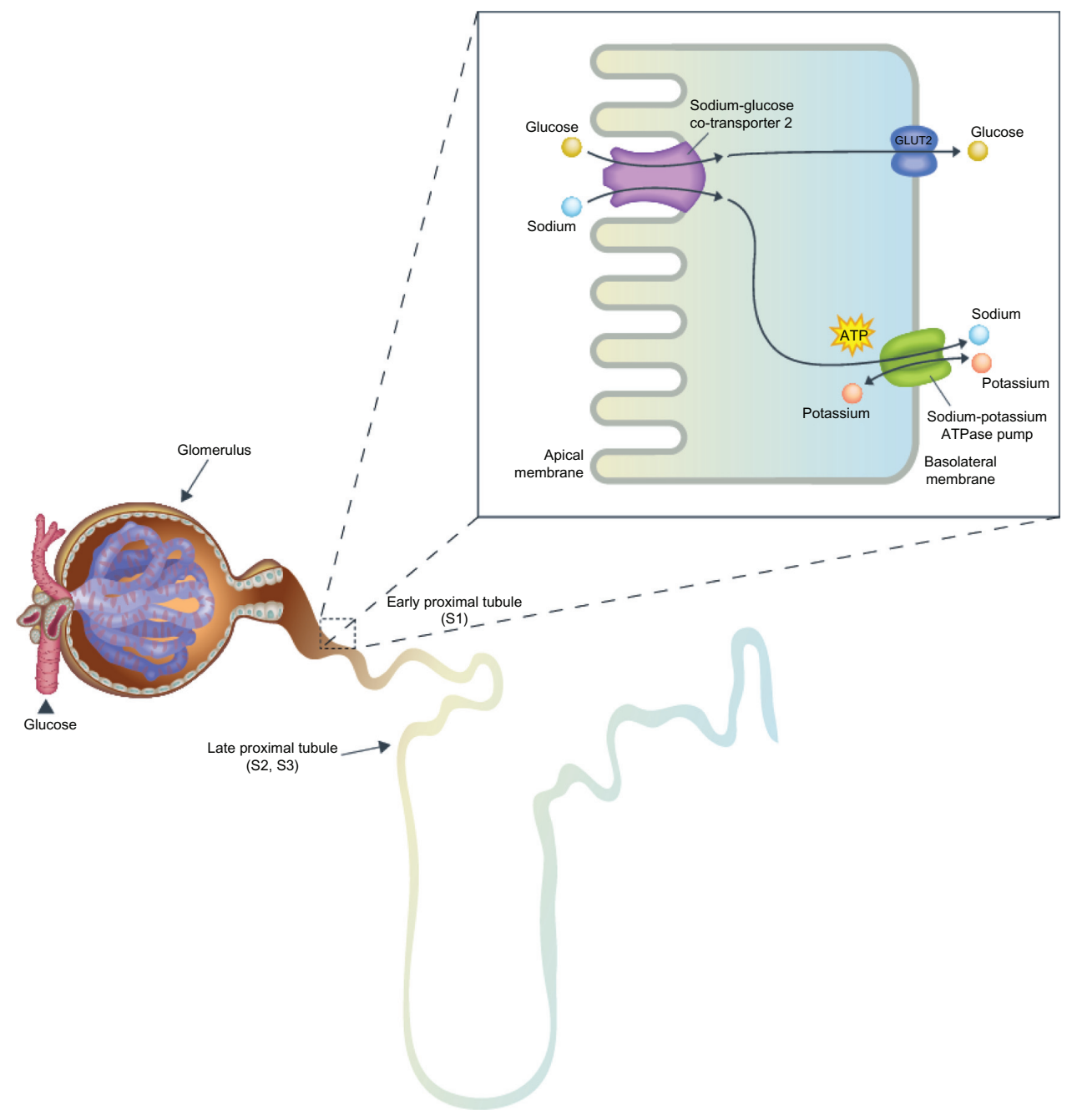

Figure I The kidneys' role in glucose reabsorption.

Abbreviations: GLUT, glucose transporter; ATP, adenosine triphosphate; ATPase, adenosine triphosphatase; SI, segment I; S2, segment 2; S3, segment 3. 
and utilization. ${ }^{6}$ Many organs are involved in glucose homeostasis and the kidneys are now recognized as a major contributor to both gluconeogenesis and glucose reabsorption. ${ }^{3,6}$ This review will focus specifically on the kidneys' role in glucose reabsorption, how it is altered in diabetics, and how it is an advantageous target for the treatment of diabetes (Figure 1).

The kidney contributes to glucose homeostasis by filtering and reabsorbing glucose back into the circulatory system. ${ }^{6}$ In non-diabetics, approximately $180 \mathrm{~g}$ of glucose is freely filtered by the glomeruli each day, which is essentially all reabsorbed in the proximal convoluted tubule (Figure 1). ${ }^{3,6}$ In order for glucose, a polar compound, to be reabsorbed or transported across the cell from the lumen into the blood circulation, membrane-associated carrier proteins are necessary.,6 Two transporter families are involved with glucose reabsorption, facilitated glucose transporters (GLUTs), which function as passive transporters, and sodium glucose cotransporters (SGLTs), which are secondary active co-transporters. ${ }^{3,6}$ There are two types of SGLTs: SGLT1, a low capacity, high affinity transporter located primarily in the small intestine, as well as in the renal proximal convoluted tubule, and SGLT2, a high capacity, low affinity transporter found in the early proximal convoluted tubule. ${ }^{6-8}$ SGLT2s, found exclusively in the early proximal convoluted tubule (segment 1 and 2), are accountable for approximately $90 \%$ of glucose reabsorption. ${ }^{6}$ The remaining $10 \%$ of glucose is reabsorbed by SGLT1 in the later portion of the convoluted tubule (segment 3). ${ }^{6,7}$ Once the capacity ( $\sim 350 \mathrm{mg}$ glucose/minute) of these transporters is exceeded, occurring around a blood glucose concentration of approximately $10.0-11.1 \mathrm{mmol} / \mathrm{L}$ in healthy individuals, glucose begins to be excreted in the urine., ${ }^{3,6}$ This capacity for glucose reabsorption increases in diabetics due to the upregulation of SGLT2 and GLUT2 in the proximal tubule, resulting in hyperglycemia and reduced glucosuria. ${ }^{3}$

\section{History of renal glucose transporter inhibitors}

The concept of inhibiting glucose reabsorption evolved from the discovery of inherited and acquired diseases whereby renal glucose handling is altered such that copious amounts of glucose are excreted. ${ }^{6}$ The two main causes of naturally occurring renal glucosuria are familial (primary) renal glucosuria (FRG), resulting from SGLT2 mutations (incidence of $1 / 20,000$ persons in the US), and glucose-galactose malabsorption (GGM), resulting from SGLT1 mutations (approximately 300 individuals affected to date worldwide). ${ }^{3,6,9,10}$ Besides significant glucosuria, patients with FRG have no significant physical or clinical manifestations and are therefore considered to have benign glucosuria. ${ }^{3,6}$ On the other hand, patients with GGM have severe gastrointestinal (GI) symptoms that manifest within the first few days after birth and result from the inability to absorb glucose and galactose from the intestinal tract, leading to severe diarrhea and dehydration, that may be fatal if a glucose- and galactose-free diet is not initiated. ${ }^{3,6}$ The glucosuria in patients with GGM is very mild, demonstrating that a majority of renal glucose reabsorption occurs through SGLT2 and inhibition of SGLT2 exclusively will minimize any untoward GI adverse events (AEs). ${ }^{6}$ Furthermore, we know that patients with FRG and chronic glucosuria are generally healthy and do not present with associated adverse consequences, indicating that SGLT2 inhibitors are exciting targets for the management of DM. ${ }^{6}$

The mechanism of action of the SGLT2 inhibitors will herald a significant change in the perception of glucosuria. As previously mentioned, once the capacity of SGLT2 transporters is exceeded, glucose begins to be excreted in the urine. ${ }^{4,6}$ Historically, glucosuria was indicative of poor glucose control. However, due to the unique mechanism of SGLT2 inhibitors inhibiting renal glucose reabsorption at elevated glucose concentrations, the presence of glucosuria indicates that SGLT2 inhibition is transferring glucose from the blood to the urine, essentially siphoning the glucose away from the delicate endothelium and organs susceptible to its noxious effects. Conversely, in the absence of such inhibition, glucosuria indicates a spillover of glucose from the blood to the urine, signifying elevated plasma glucose and potential for target organ damage.

Phlorizin was the first SGLT inhibitor discovered (in 1835 ) and is a naturally occurring compound isolated from the bark of apple trees. ${ }^{6-8}$ It works in the kidneys to increase glucose excretion, but is not suitable for clinical use due to its poor oral bioavailability and GI AEs, such as severe diarrhea. ${ }^{3,6-8}$ It is now known that the GI AEs accompanying this compound are due to its lack of specificity for SGLT2 and actions on SGLT1, found mainly in the small intestine. ${ }^{6-8}$ Phlorizin's poor bioavailability led to the development of T-1095A, a derivative of phlorizin, possessing better stability, but still having a lack of selectivity for SGLT2, which led to its discontinuation after Phase II studies. ${ }^{6,7}$ The failure of T-1095A was followed by sergliflozin and many other SGLT inhibitor compounds, these being more selective for SGLT2 ${ }^{6,7}$ Amongst all of the SGLT2 inhibitor compounds synthesized, some continue to be studied in clinical trials, while most were 
discontinued at some point in their clinical development program for various reasons (Figure 2 ) ${ }^{6}$

\section{SGLT2 inhibitors under clinical development}

Due to the novel mechanism of SGLT2 inhibitors, numerous compounds are entangled in a race to market with the ultimate goal of emerging first to market or arriving with a distinct in-class advantage. However, canagliflozin has recently received US Food and Drug Administration (FDA) approval. ${ }^{11}$ Figure 2 lists many of the SGLT2 inhibitors currently undergoing clinical trials; however, this review will focus mainly on the three agents furthest in development, dapagliflozin, canagliflozin, and empagliflozin (listed in order of submission or possible submission of New Drug Application [NDA] to the FDA). Supplementary data, including the clinical efficacy and safety for dapagliflozin, canagliflozin, and empagliflozin, can be found online (www. eastcoastresearch.net/\#/sglt2inhibitor/).

\section{Dapagliflozin}

Dapagliflozin (Forxiga ${ }^{\circledR}$; Bristol-Myers Squibb, New York, NY, USA; AstraZeneca, London, UK) was the first SGLT2 inhibitor to have its NDA submitted to the FDA (December 2010). ${ }^{12}$
However, on January 19, 2012 the FDA declined approval of dapagliflozin and issued a complete response letter requesting "additional clinical data to allow a better assessment of the benefit-risk profile" for dapagliflozin. ${ }^{13}$ This includes clinical trial data from ongoing studies and may require information from new clinical trials. This decline of approval followed the July 19, 2011 FDA advisory committee meeting when members voted nine to six against approval of the agent, largely due to the concern of a cancer signal, specifically for breast and bladder cancers. ${ }^{13}$ Although animal studies with dapagliflozin showed no evidence of cancer, this does not disqualify the possibility that elevated levels of glucose in the bladder accelerate the rate of growth for preexisting cancers. In clinical trials, the majority of patients who experienced bladder cancer had hematuria at baseline, indicating that some cancers were likely preexistent. ${ }^{13-15}$ On November 12, 2012 the European Commission approved use of dapagliflozin $10 \mathrm{mg}$ once daily in type 2 diabetics to improve glycemic control as monotherapy when diet and exercise alone do not provide adequate glycemic control in patients for whom use of metformin is considered inappropriate due to intolerance. ${ }^{16}$ Dapagliflozin $10 \mathrm{mg}$ once daily was also approved in Europe as add-on therapy with metformin, a sulfonylurea (SU), or with insulin ( \pm oral antidiabetic drugs [OADs]), together with diet and exercise, when these agents do

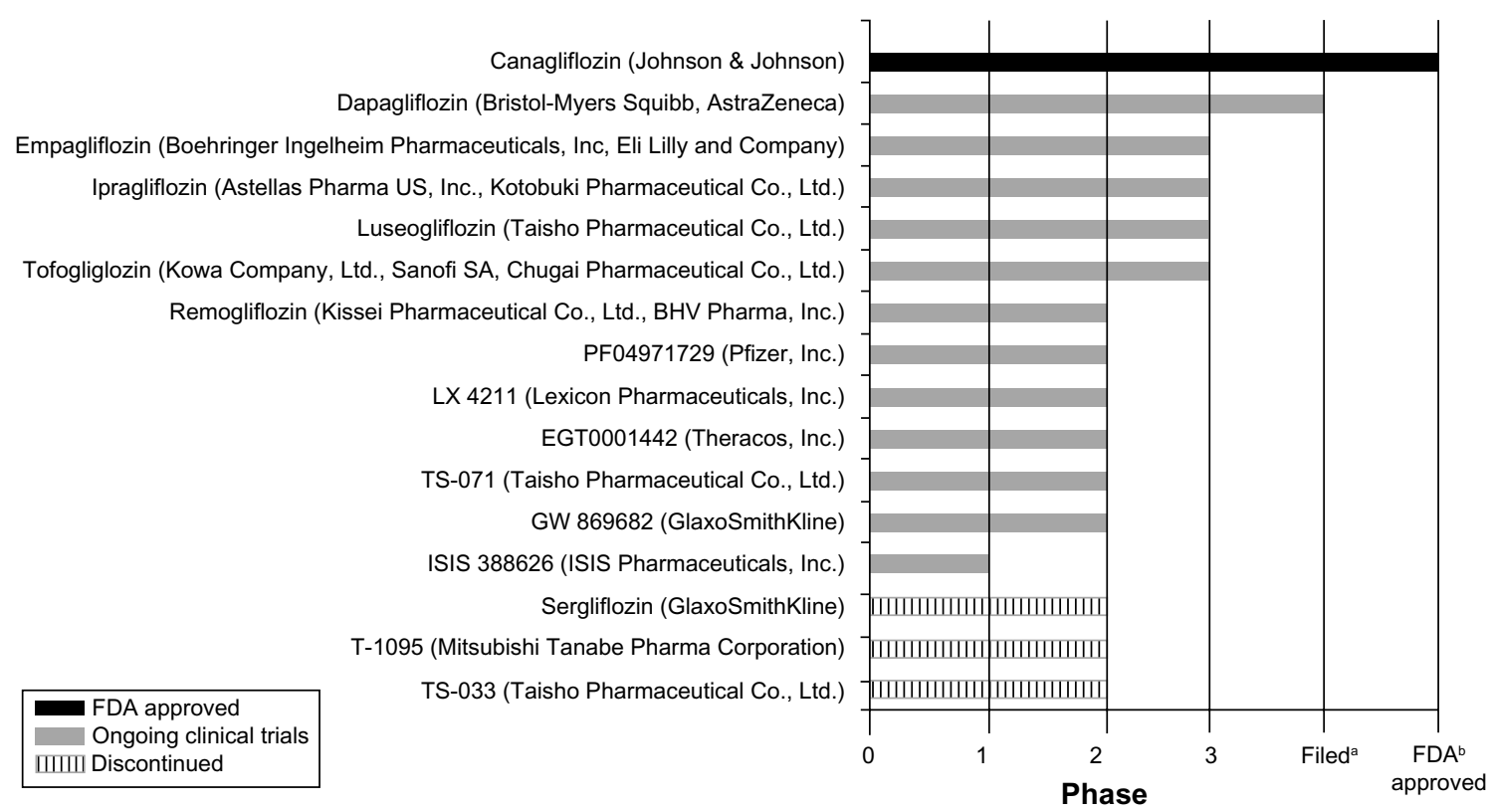

Figure 2 SGLT2 inhibitors in development.

Notes: ${ }^{2}$ Dapagliflozin: FDA declined approval January 19, 2012 and issued a complete response letter requesting additional clinical data on the benefit-risk profile due to the concern of a cancer signal; 'banagliflozin: FDA approved March 29, 2013. Johnson \& Johnson (New Brunswick, NJ, USA); Bristol-Myers Squibb (New York, NY, USA); AstraZeneca (London, UK); Boehringer Ingelheim Pharmaceuticals, Inc (Ingelheim, Germany); Eli Lilly and Company (Indianapolis, IN, USA); Astellas Pharma US, Inc. (Northbrook, IL, USA); Kotobuki Pharmaceutical Co., Ltd. (Hanishina, Japan); Taisho Pharmaceutical Co., Ltd. (Tokyo, Japan); Kowa Company, Ltd. (Nagoya, Japan); Sanofi SA (Paris, France); Chugai Pharmaceutical Co., Ltd. (Tokyo, Japan); Kissei Pharmaceutical Co., Ltd. (Matsumoto City, Japan); BHV Pharma, Inc. (Research Triangle Park, NC, USA); Pfizer, Inc. (New York, NY, USA); Lexicon Pharmaceuticals, Inc. (The Woodlands, TX, USA); Theracos, Inc. (Marlborough, MA, USA); GlaxoSmithKline (London, UK); ISIS Pharmaceuticals, Inc. (Carlsbad, CA, USA); and Mitsubishi Tanabe Pharma Corporation (Osaka, Japan).

Abbreviations: FDA, Food and Drug Administration; SGLT2, sodium glucose co-transporter 2. 
not provide adequate glycemic control. ${ }^{16}$ Dapagliflozin doses of 2.5, 5, 10, 20, and $50 \mathrm{mg}$ have been studied in Phase III studies; however, only the results the of $5 \mathrm{mg}$ and $10 \mathrm{mg}$ doses will be presented as they are the most relevant doses and the ones most likely to be used clinically. ${ }^{17-32}$

Dapagliflozin has an extensive Phase III clinical development program that assesses both the efficacy and safety of the agent amongst a wide range of type 2 diabetics as monotherapy, add-on therapy with metformin, SU, pioglitazone, metformin and SU, metformin and sitagliptin, and as add-on therapy with insulin (with or without other antihyperglycemic agents [AHAs] $).{ }^{17-32}$ Phase III studies also examined dapagliflozin in special populations such as those with moderate renal impairment (estimated glomerular filtration rate [eGFR] $\geq 30$ to $\leq 59 \mathrm{~mL} /$ minute $/ 1.73 \mathrm{~m}^{2}$ ) and those with documented $\mathrm{CV}$ disease and hypertension. ${ }^{16}$

Phase III results demonstrated that dapagliflozin was effective in reducing hemoglobin $\mathrm{A}_{1 \mathrm{c}}\left(\mathrm{HbA}_{1 \mathrm{c}}\right)$ as monotherapy, dual therapy, and triple therapy with oral agents, as well as with combination therapy with insulin with or without oral AHAs. ${ }^{17-32}$ Throughout all Phase III studies, dapagliflozin $5 \mathrm{mg}$ and $10 \mathrm{mg}$ once daily both resulted in significant $\mathrm{HbA}_{1 \mathrm{c}}$ reductions compared to a placebo or active comparator. ${ }^{17-32}$

After 12 weeks and 24 weeks of therapy, $\mathrm{HbA}_{1 \mathrm{c}}$ was decreased by $-0.72 \%$ and $-0.77 \%$ with dapagliflozin $5 \mathrm{mg}$ and by $-0.85 \%$ and $-0.89 \%$ with dapagliflozin $10 \mathrm{mg}$, in type 2 diabetics inadequately controlled with diet and exercise alone compared to placebo $(-0.18 \%$ and $-0.23 \% ; P<0.001) .{ }^{17,18}$ Fasting plasma glucose (FPG) reductions were apparent at week 1 and continued to significantly decrease with dapagliflozin $5 \mathrm{mg}$ and $10 \mathrm{mg}$ at week 12 compared to placebo $(-1.05 \mathrm{mmol} / \mathrm{L}$ and $-1.17 \mathrm{mmol} / \mathrm{L}$ versus $-0.33 \mathrm{mmol} / \mathrm{L} ; P=0.005$ and 0.002 , respectively) and at week 24 compared to placebo $(-1.34 \mathrm{mmol} / \mathrm{L}$ and $-1.60 \mathrm{mmol} / \mathrm{L}$ versus $-0.23 \mathrm{mmol} / \mathrm{L} ; P=0.0005$ and $<0.0001$, respectively). ${ }^{17,18}$ Although not statistically significant, after 12 to 24 weeks of therapy, a greater proportion of patients treated with dapagliflozin $5 \mathrm{mg}$ and $10 \mathrm{mg}$ reached a target $\mathrm{HbA}_{1 \mathrm{c}}$ of $<7.0 \%$ compared to placebo $(40 \%-44 \%$ and $51 \%-52 \%$ versus $32 \% ; P=$ not significant). ${ }^{17,18}$ After 102 weeks of therapy, dapagliflozin $5 \mathrm{mg}$ and $10 \mathrm{mg}$ sustained clinical meaningful reductions compared to placebo in both $\mathrm{HbA}_{1 \mathrm{c}}(-0.71 \%$ and $-0.61 \%$ versus $-0.17 \%)$ and FPG $(-1.08 \mathrm{mmol} / \mathrm{L}$ and $-1.50 \mathrm{mmol} / \mathrm{L}$ versus $-0.38 \mathrm{mmol} / \mathrm{L}) .{ }^{19}$ A greater number of patients achieved a goal $\mathrm{HbA}_{1 \mathrm{c}}$ of $<7.0 \%$ with dapagliflozin $5 \mathrm{mg}$ and $10 \mathrm{mg}$ compared to placebo $(34.4 \%$ and $26.2 \%$ versus $19.4 \%) .{ }^{19}$

The efficacy of dapagliflozin was persistent when added-on to metformin. ${ }^{20-25}$ Initial reductions in $\mathrm{HbA}_{1 \mathrm{c}}$ seen at 24 weeks with dapagliflozin $5 \mathrm{mg}$ or $10 \mathrm{mg}$ added to metformin were sustained through 102 weeks and were greater than placebo $(-0.58 \%$ and $-0.78 \%$ versus $0.02 \%){ }^{24,25}$ FPG decreases with both doses of dapagliflozin were also maintained throughout 102 weeks of therapy, and were better than placebo $(-1.47 \mathrm{mmol} / \mathrm{L}$ and $-1.36 \mathrm{mmol} / \mathrm{L}$ versus $-0.58 \mathrm{mmol} / \mathrm{L}) .{ }^{24,25}$ When added to metformin, the reduction in $\mathrm{HbA}_{1 \mathrm{c}}$ with dapagliflozin titrated to maximum tolerated dose (target dose $10 \mathrm{mg}$ daily) was found to be non-inferior to glipizide at the maximum tolerated dose (target dose $20 \mathrm{mg}$ daily) (both $-0.52 \%$; confidence interval $[\mathrm{CI}]:-0.60,-0.44)$ after 52 weeks of therapy. ${ }^{23}$ During the initial titration period, glipizide had greater $\mathrm{HbA}_{1 \mathrm{c}}$ reductions compared to dapagliflozin, except glipizide effects diminished during the remaining 52 week maintenance period, while dapagliflozin's effects remained stable. ${ }^{23}$ Dapagliflozin's $\mathrm{HbA}_{1 \mathrm{c}}$ reduction was sustained over 104 weeks during the extension study, while glipizide's $\mathrm{HbA}_{1 \mathrm{c}}$ reduction was attenuated at 104 weeks $\left(-0.32 \%\right.$ versus $-0.14 \%$, respectively). ${ }^{20-22}$ Similar results occurred with FPG; initial FPG reduction with dapagliflozin continued at 104 weeks, while glipizide's FPG reduction lessened at 104 weeks $(-1.12 \mathrm{mmol} / \mathrm{L}$ versus $-0.68 \mathrm{mmol} / \mathrm{L}$, respectively). ${ }^{20-22}$

Numerically larger decreases in both $\mathrm{HbA}_{1 \mathrm{c}}(-0.63 \%$ and $-0.82 \%)$ and FPG $(-1.18 \mathrm{mmol} / \mathrm{L}$ and $-1.58 \mathrm{mmol} / \mathrm{L})$ were observed after 24 weeks with dapagliflozin $5 \mathrm{mg}$ and $10 \mathrm{mg}$ when added to glimepiride compared to placebo $\left(\mathrm{HbA}_{1 \mathrm{c}}=-0.13 \%, \mathrm{FPG}=-0.11 \mathrm{mmol} / \mathrm{L} ; P<0.0001\right.$ for both doses). ${ }^{26}$ A larger proportion of patients were able to achieve target $\mathrm{HbA}_{1 \mathrm{c}}<7.0 \%$ with both doses of dapagliflozin in combination with glimepiride compared to placebo $(30.3 \%-32.7 \%$ versus $12.6 \% ; P \leq 0.0001) .{ }^{26}$ Dapagliflozin $5 \mathrm{mg}$ and $10 \mathrm{mg}$ once daily added to pioglitazone $\geq 30 \mathrm{mg}$ once daily resulted in statistically significant reductions in $\mathrm{HbA}_{1 \mathrm{c}}$ after 24 weeks of therapy, which was maintained through 48 weeks of therapy, compared to placebo $(-0.95 \%$ and $-1.21 \%$ versus $-0.54 \%) .{ }^{27-29}$ Rapid decreases in FPG were seen after 1 week on treatment with either dose of dapagliflozin in addition to pioglitazone and were sustained throughout 48 weeks of therapy $(-1.27 \mathrm{mmol} / \mathrm{L}$ and $-1.84 \mathrm{mmol} / \mathrm{L}$ versus $0.73 \mathrm{mmol} / \mathrm{L}) .{ }^{27-29}$

Dapagliflozin $5 \mathrm{mg}$ and $10 \mathrm{mg}$ added to insulin therapy with or without OADs resulted in significant decreases in $\mathrm{HbA}_{1 \mathrm{c}}$ compared to placebo over 48 weeks (insulin only: $-0.89 \%$ and $-0.96 \%$ versus $-0.50 \%$; insulin with OADs: $-1.02 \%$ and $-1.04 \%$ versus $-0.44 \%$ ), with the most rapid decreases seen over the first 8 weeks. ${ }^{30}$ Daily insulin requirements increased over 48 weeks in the placebo group (10.54 units), whereas no increases were found with dapagliflozin treatment $(-0.69$ to 0.30 units; $P<0.001) .{ }^{30}$ After 48 weeks of therapy, those randomized to dapagliflozin were 
switched to $10 \mathrm{mg}$ daily and the enhanced $\mathrm{HbA}_{1 \mathrm{c}}$ reduction with dapagliflozin compared to placebo was sustained over 104 weeks (placebo-adjusted: $-0.35 \%$ to $-0.39 \%$ ). ${ }^{31,32}$ Over the 104 week treatment period, $50.4 \%$ of patients in the placebo arm required insulin up-titration compared to $25.5 \%$ to $26.5 \%$ of patients treated with dapagliflozin. ${ }^{31,32}$

\section{Canagliflozin}

Canagliflozin (Invokana ${ }^{\circledR}$; Janssen Research and Development, LLC, Raritan, NJ, USA; Mitsubishi Tanabe Pharma Corporation, Osaka, Japan) was FDA approved March 29, 2013 to be used with diet and exercise, to improve glycemic control in adults with type 2 diabetes. ${ }^{11}$ However, the FDA is requiring five post-marketing studies for canagliflozin, including a CV outcomes trial, an enhanced pharmacovigilance program (to monitor for malignancies, serious cases of pancreatitis, severe hypersensitivity reactions, photosensitivity reactions, liver abnormalities, and adverse pregnancy outcomes), a bone safety study, and two pediatric studies. ${ }^{33}$ Canagliflozin was first reviewed by the FDA January 10, 2013 for approval of its NDA, after its submission to the FDA May 31, 2012. At that time, the FDA advisory panel voted ten to five in favor of approving canagliflozin; however, they also voted eight to seven that they had concerns about the CV safety of the agent. ${ }^{34}$ Canagliflozin has an extensive Phase III clinical development program that assesses both the efficacy and safety of the agent in a wide range of type 2 diabetics as monotherapy, add-on therapy with metformin, $\mathrm{SU}$, metformin and SU, metformin and pioglitazone, and as add-on therapy with insulin (with or without other AHAs). ${ }^{35-46}$ Phase III studies also examined canagliflozin in special populations such as those with renal impairment (eGFR $\geq 30$ to $<50 \mathrm{~mL} /$ minute $/ 1.73 \mathrm{~m}^{2}$ ), the elderly, and those with or at high risk for $\mathrm{CV}$ complications. ${ }^{11}$

Phase III results demonstrated that canagliflozin was effective in reducing $\mathrm{HbA}_{1 \mathrm{c}}$ as monotherapy, dual therapy, and triple therapy with oral agents, as well as with combination therapy with insulin with or without oral AHAs. ${ }^{35-46}$ Throughout all Phase III studies, canagliflozin $100 \mathrm{mg}$ and $300 \mathrm{mg}$ once daily both resulted in significant $\mathrm{HbA}_{1 \mathrm{c}}$ reductions compared to a placebo or active comparator, with slightly greater reductions with canagliflozin $300 \mathrm{mg}$ once daily. ${ }^{35-46}$

After 26 weeks of therapy, canagliflozin $100 \mathrm{mg}$ and $300 \mathrm{mg}$ once daily significantly reduced $\mathrm{HbA}_{1 \mathrm{c}}(-0.77 \%$ and $-1.03 \%$, respectively) in type 2 diabetics inadequately controlled with diet and exercise alone compared to placebo $(0.14 \% ; P<0.001) .{ }^{35}$ FPG was also significantly decreased by $-1.50 \mathrm{mmol} / \mathrm{L}$ to $-1.90 \mathrm{mmol} / \mathrm{L}$ with both doses of canagliflozin (placebo $=0.50 \mathrm{mmol} / \mathrm{L} ; P<0.001$ ), resulting in a greater proportion of patients reaching a target $\mathrm{HbA}_{1 \mathrm{c}}$ of $<7.0 \%$ compared to placebo ( $44.5 \%$ to $62.4 \%$ versus $20.6 \%$; $P<0.001) .{ }^{35}$ Amongst a subset population who completed a frequently-sampled mixed-meal tolerance test (FS-MMTT), canagliflozin improved indices of beta-cell function (BCF). ${ }^{36}$ Both doses markedly reduced plasma glucose during the FS-MMTT, in contrast to small increases observed with placebo. Canagliflozin treatment also resulted in substantial increases in the $\mathrm{AU}_{\mathrm{C}} / \mathrm{AU}_{\mathrm{G}}$ ratio, insulin secretion rate (ISR), and beta-cell glucose sensitivity from baseline in contrast to the slight decreases seen with placebo. ${ }^{36}$ However, C-peptide concentrations were nearly identical before and after treatment across all treatment arms. ${ }^{36}$

The efficacy of canagliflozin was sustained when added-on to metformin. ${ }^{37-39}$ Canagliflozin $100 \mathrm{mg}$ or $300 \mathrm{mg}$ once daily added to metformin was found to be non-inferior to glimepiride and metformin combination, and canagliflozin $300 \mathrm{mg}$ once daily provided greater $\mathrm{HbA}_{1 \mathrm{c}}$ reductions compared with glimepiride $(-0.93 \%$ versus $-0.81 \%$; 95\% CI: $-0.22,-0.02) .{ }^{37-39}$ Numerically larger decreases in FPG were observed after 52 weeks with both doses of canagliflozin when measured against glimepiride $(-1.35 \mathrm{mmol} / \mathrm{L}$ to $-1.53 \mathrm{mmol} / \mathrm{L}$ versus $-1.02 \mathrm{mmol} / \mathrm{L})$, and while canagliflozin showed sustained decreases over the entire treatment period, increases with glimepiride after week 18 were detected. ${ }^{37-39}$ Despite greater reductions in $\mathrm{HbA}_{1 \mathrm{c}}$ and FPG with canagliflozin, similar proportions of patients achieved a $\mathrm{HbA}_{1 \mathrm{c}}$ of less than $7 \%$ with canagliflozin or glimepiride when added to metformin (53.6\% to $60.1 \%$ versus $55.8 \%$, respectively). ${ }^{37-39}$

Canagliflozin $100 \mathrm{mg}$ or $300 \mathrm{mg}$ once daily added to patients inadequately controlled on metformin and an SU significantly reduced $\mathrm{HbA}_{1 \mathrm{c}}(-0.85 \%$ to $-1.06 \%$ versus $-0.13 \%$; $P<0.001)$ and FPG $(-1.01 \mathrm{mmol} / \mathrm{L}$ to $-1.69 \mathrm{mmol} / \mathrm{L}$ versus $0.23 \mathrm{mmol} / \mathrm{L} ; P<0.001)$ compared to placebo. ${ }^{40,41}$ A greater proportion of patients treated with canagliflozin achieved an $\mathrm{HbA}_{1 \mathrm{C}}$ of $<7.0 \%$ when evaluated against placebo ( $43.2 \%$ to $56.6 \%$ versus $18.0 \% ; P<0.001)$ as add-on therapy to metformin plus an SU and patients required less glycemic rescue therapy $(1.3 \%$ to $1.9 \%$ versus $12.8 \%$; $P<0.001) .{ }^{40,41}$ When comparing canagliflozin $300 \mathrm{mg}$ once daily combination with metformin and an SU to sitagliptin in addition to metformin and an SU, canagliflozin $300 \mathrm{mg}$ had a greater $\mathrm{HbA}_{1 \mathrm{c}}$ reduction compared to sitagliptin $100 \mathrm{mg}$ daily after 52 weeks $(-1.03 \%$ versus $0.66 \%$, respectively; $95 \% \mathrm{CI}:-0.50,-0.25)$, as well as greater reductions in 
FPG $(-1.66 \mathrm{mmol} / \mathrm{L}$ versus $-0.33 \mathrm{mmol} / \mathrm{L}$ for canagliflozin versus sitagliptin, respectively; $P<0.001) .{ }^{42,43}$ In addition, more patients treated with canagliflozin $300 \mathrm{mg}$ once daily reached an $\mathrm{HbA}_{1 \mathrm{c}}$ of $<7.0 \%$ compared to sitagliptin $100 \mathrm{mg}$ daily (47.6\% versus $35.3 \%$ ) when either are added to metformin and an $\mathrm{SU} .{ }^{42,43}$ A subgroup of patients from the study comparing the addition of canagliflozin to metformin and an SU versus placebo were included in the FS-MMTT analysis, which demonstrated both doses of canagliflozin markedly reduced plasma glucose during the FS-MMTT, whereas placebo only resulted in slight decreases. ${ }^{44}$ However, as was seen in the subset of patients who underwent the FSMMT in the canagliflozin monotherapy study, C-peptide concentrations were almost equal before and after treatment when canagliflozin was added on to metformin plus SU. ${ }^{44}$ In addition, both doses of canagliflozin showed increases in the $\mathrm{AU}_{\mathrm{C}} / \mathrm{AU}_{\mathrm{G}}$ ratio, ISR, and beta-cell glucose sensitivity from baseline in contrast to slight decreases in the $\mathrm{AU}_{\mathrm{C}} / \mathrm{AU}_{\mathrm{G}}$ ratio and minimal to no change in ISR and beta-cell glucose sensitivity seen with placebo. ${ }^{44}$

Canagliflozin $100 \mathrm{mg}$ and $300 \mathrm{mg}$ once daily added on to metformin and pioglitazone reduced $\mathrm{HbA}_{1 \mathrm{c}}$ significantly more than placebo $(-0.89 \%$ and $-1.03 \%$ versus $-0.26 \%$, respectively; $P<0.001)$, as well as FPG $(-1.49 \mathrm{mmol} / \mathrm{L}$ and $-1.84 \mathrm{mmol} / \mathrm{L}$ versus $0.14 \mathrm{mmol} / \mathrm{L}$, respectively; $P<0.001) .{ }^{45}$ After 26 weeks of therapy, a greater proportion of patients treated with canagliflozin $100 \mathrm{mg}$ or $300 \mathrm{mg}$ once daily achieved an $\mathrm{HbA}_{1 \mathrm{c}}$ of $<7.0 \%$ compared to placebo (46.9\% and $64.3 \%$ versus $32.5 \%$, respectively; $P<0.01$ ). ${ }^{45}$ Both canagliflozin doses significantly increased Homeostasis Model Assessment-BCF (HOMA2-\%B) compared to placebo (15.2 to 18.1 versus 0.9 , respectively; $P<0.001$ ), indicating that canagliflozin improved $\mathrm{BCF}^{45}$

An analysis from a subgroup of patients from the Canagliflozin Cardiovascular Assessment Study (CANVAS) who had a history or high risk of CV disease found canagliflozin $100 \mathrm{mg}$ or $300 \mathrm{mg}$ once daily led to further reductions in $\mathrm{HbA}_{1 \mathrm{c}}$ when added to insulin ( $\geq 30 \mathrm{IU}$ daily) with or without other AHAs $(-0.63 \%$ and $-0.72 \%$ versus $-0.01 \%$, respectively; $P<0.001) .{ }^{46}$ Significant reductions were also seen in FPG with the addition of canagliflozin $100 \mathrm{mg}$ or $300 \mathrm{mg}$ once daily $(-1.00 \mathrm{mmol} / \mathrm{L}$ and $-1.40 \mathrm{mmol} / \mathrm{L}$ versus $0.20 \mathrm{mmol} / \mathrm{L} ; P<0.001){ }^{46}$

Canagliflozin has FDA approved doses of $100 \mathrm{mg}$ and $300 \mathrm{mg}$ and the recommended starting dose is $100 \mathrm{mg}$ once daily, taken before the first meal of the day. ${ }^{11}$ The dose can be increased to $300 \mathrm{mg}$ once daily in patients tolerating $100 \mathrm{mg}$ once daily who have an eGFR of $\geq 60 \mathrm{~mL} /$ minute and require additional glycemic control. ${ }^{11}$ Canagliflozin is limited to $100 \mathrm{mg}$ once daily in patients with an eGFR of 45-60 $\mathrm{mL} / \mathrm{minute}$ and should not be started/should be discontinued if a patient's eGFR is $<45 \mathrm{~mL} /$ minute. $^{11}$ Canagliflozin is contraindicated in patients with severe renal impairment, end stage renal disease, or are on dialysis. ${ }^{11}$

\section{Empagliflozin}

Empagliflozin (Boehringer Ingelheim Pharmaceuticals, Inc, Ingelheim, Germany; Eli Lilly and Company, Indianapolis, IN, USA) is on schedule to file for NDA submission to the FDA in 2013. Boehringer Ingelheim and Eli Lilly and Company announced January 7, 2013 top-line results from four of empagliflozin's Phase III studies, all of which met their primary endpoints. ${ }^{47}$ Empagliflozin has a comprehensive Phase III clinical development program, consisting of eight multinational clinical trials, including a large CV outcome trial. ${ }^{47}$ The Phase III program assesses the efficacy and safety of the agent amongst a wide range of type 2 diabetics as monotherapy, add-on therapy with metformin, pioglitazone, metformin and SU, metformin and pioglitazone, metformin and linagliptin, as add-on therapy with insulin (with or without other AHAs), and in a population of patients with mild, moderate, or severe renal impairment. ${ }^{47}$ Phase III results demonstrated that empagliflozin was effective in reducing $\mathrm{HbA}_{1 \mathrm{c}}$ as monotherapy, dual therapy, and triple therapy with OADs. ${ }^{48-50}$ Data for empagliflozin doses of $10 \mathrm{mg}$ and $25 \mathrm{mg}$ daily are presented here as these are the doses being studied in Phase III clinical trials.

After 12 weeks of therapy, empagliflozin $10 \mathrm{mg}$ and $25 \mathrm{mg}$ daily in type 2 diabetics inadequately controlled with diet and exercise showed a dose-dependent and statistically significant reduction in $\mathrm{HbA}_{1 \mathrm{c}}(-0.48 \%$ and $-0.63 \%)$ and FPG (-1.60 mmol/L and $-1.73 \mathrm{mmol} / \mathrm{L})$ compared to placebo $\left(\mathrm{HbA}_{1 \mathrm{c}}=0.09 ; \mathrm{FPG}=0.04 \mathrm{mmol} / \mathrm{L}\right) .{ }^{48}$ Empagliflozin $25 \mathrm{mg}$ daily showed a comparable decrease in $\mathrm{HbA}_{1 \mathrm{c}}$ to metformin $(-0.63 \%$ and $-0.75 \%$, respectively) and a comparable proportion of patients achieving a $\mathrm{HbA}_{1 \mathrm{c}}<7.0 \%(45.1 \%$ and $45.0 \%$, respectively). ${ }^{48}$ The benefits obtained with empagliflozin $10 \mathrm{mg}$ and $25 \mathrm{mg}$ daily monotherapy were sustained after 90 weeks of therapy $\left(\mathrm{HbA}_{1 \mathrm{c}}=-0.34 \%\right.$ and $-0.47 \%$, respectively) compared to metformin $\left(\mathrm{HbA}_{1 \mathrm{c}}=-0.56 \%\right) .{ }^{49} \mathrm{FPG}$ was also significantly decreased by $-1.69 \mathrm{mmol} / \mathrm{L}$ to $-1.54 \mathrm{mmol} / \mathrm{L}$ with both doses of empagliflozin compared to metformin $(1.44 \mathrm{mmol} / \mathrm{L}) .{ }^{49}$ The efficacy of empagliflozin was sustained when added-on to metformin. ${ }^{49,50}$ After 12 weeks of therapy, empagliflozin $10 \mathrm{mg}$ or $25 \mathrm{mg}$ daily in combination with metformin 
provided greater $\mathrm{HbA}_{1 \mathrm{c}}$ reductions compared with placebo $(-0.56 \%$ and $-0.55 \%$ versus $0.15 \% ; P<0.0001)$, as well as reductions in FPG $(-1.23 \mathrm{mmol} / \mathrm{L}$ and $-1.49 \mathrm{mmol} / \mathrm{L}$ versus $0.26 \mathrm{mmol} / \mathrm{L} ; P<0.0001) .{ }^{50}$ These decreases in $\mathrm{HbA}_{1 \mathrm{c}}$ with both empagliflozin doses trended toward greater reductions than sitagliptin $\left(\mathrm{HbA}_{1 \mathrm{c}}=-0.45 \%\right)$ and the reductions in $\mathrm{FPG}$ with empagliflozin $25 \mathrm{mg}$ daily were significantly greater than those with sitagliptin $(\mathrm{FPG}=-0.68 \mathrm{mmol} / \mathrm{L}) .{ }^{50}$ The effects of empagliflozin $10 \mathrm{mg}$ or $25 \mathrm{mg}$ daily added to metformin were sustained over 90 weeks and provided greater $\mathrm{HbA}_{1 \mathrm{c}}$ reductions compared with sitagliptin $(-0.34 \%$ to $-0.63 \%$ versus $-0.40 \%) .{ }^{49}$ Numerically larger decreases in FPG were observed after 90 weeks with both doses of empagliflozin when measured up against sitagliptin $(-1.18 \mathrm{mmol} / \mathrm{L}$ to $-1.76 \mathrm{mmol} / \mathrm{L}$ versus $-0.87 \mathrm{mmol} / \mathrm{L}$ ) and these effects were sustained over the entire treatment period. ${ }^{49}$

\section{Other SGLT2 inhibitors in development}

There are numerous other SGLT2 inhibitors in clinical development or in clinical trials. Ipragliflozin (ASP1941; Astellas Pharma US, Inc., Northbrook, IL, USA) currently has ongoing Phase III studies in Japan. ${ }^{51}$ Results from two Japanese Phase III studies demonstrated statistically significant decreases in $\mathrm{HbA}_{1 \mathrm{c}}$ compared to placebo of up to $-1.14 \%$ when used in combination with an SU alone $(P<0.001)$ and up to $-0.88 \%$ when used in addition to pioglitazone alone $(P<0.001)$ with 24 weeks of therapy. ${ }^{52}$

LX4211 (Lexicon Pharmaceuticals, Inc., The Woodlands, TX, USA) differs from the other agents in that it is a dual SGLT1/SGLT2 inhibitor. ${ }^{53}$ Historically, inhibition of SGLT1 has been purposely avoided due to the GI symptoms (eg, nausea, vomiting, abdominal pain, constipation, and diarrhea) associated with inhibition of SGLT1 in the small intestine. ${ }^{53}$ However, Phase I and Phase II studies with LX4211 in healthy and type 2 diabetic patients have demonstrated that partial inhibition of SGLT1 does not result in any additional GI symptoms compared to placebo and has less GI symptoms compared to metformin. ${ }^{53}$ A possible advantage of dual SGLT1/SGLT2 inhibition is the decrease in absorption of glucose in the small intestine, which has the potential to stimulate secretion of GLP-1, in addition to inhibition of glucose reabsorption in the kidney. ${ }^{53}$ LX4211 has completed a Phase IIb trial in type 2 diabetics and is currently undergoing a proof-of-concept study in type 2 diabetes with renal impairment and one in type 1 diabetes. ${ }^{54}$ Lexicon is expecting to begin Phase III studies in the first half of $2013 .{ }^{54}$
Tofogliflozin (CSG452; Kowa Company, Ltd., Nagoya, Japan; Sanofi SA, Paris, France; Chugai Pharmaceutical Co., Ltd., Tokyo, Japan) is currently undergoing Phase III clinical trials in Japan and completed a Phase II study in the US to evaluate its efficacy and safety for the target indication of type 2 diabetes. ${ }^{55,56}$ The results of the Phase II study in the US indicated that tofolgiflozin 5, 10, 20, and $40 \mathrm{mg}$ daily resulted in significant dose-dependent reductions in $\mathrm{HbA}_{1 \mathrm{c}}$ compared to placebo $(-0.62 \%$ to $-0.83 \%$ versus $-0.27 \%$; $P<0.001)$ along with an increase in urinary glucose excretion (UGE) as expected. ${ }^{56}$

Luseogliflozin (TS-071; Taisho Pharmaceutical Co., Ltd., Tokyo, Japan; Novartis Pharmaceuticals, Basel, Switzerland) has completed Phase II clinical trials in Japan, which confirmed sufficient blood glucose lowering and is implementing Phase III clinical trials in Japan with a planned application for type 2 DM. ${ }^{57}$

Ertugliflozin (PF04971729; Pfizer, Inc., New York, NY, USA) has completed Phase I and Phase II studies and currently does not have any active studies enrolling. ${ }^{58}$

The remaining agents, BI44847 (Boehringer Ingelheim), ISIS 388626 (ISIS Pharmaceuticals, Inc., Carlsbad, CA, USA), and GSK-1614235 (GlaxoSmithKline, London, UK) are in earlier stages of clinical development. ${ }^{59}$

\section{AEs}

Overall, the incidence of AEs with SGLT2 inhibitors, specifically dapagliflozin, canagliflozin, and empagliflozin, ranged from $57.3 \%$ to $83.0 \%$ across all studies, which is similar to that seen with metformin $(36.6 \%$ to $81.0 \%)$, metformin plus SU (68.5\% to $82.8 \%$ ), metformin plus SU and sitagliptin (77.5\%), metformin plus pioglitazone (66.1\%), SU (47.3\%), pioglitazone (66.9\%), metformin plus sitagliptin (71\%), and insulin with or without other AHAs (59.1\% to 78.2\%). ${ }^{17,19-24,26-29,31,32,37-39,42,43,46,49,50}$ Of these three SGLT2 inhibitors, although no direct headto-head comparison studies have been completed, when comparing the results of various clinical trials, dapagliflozin has the highest frequency of AEs. The occurrence of serious AEs remains very low at $1.0 \%$ to $12.6 \%$ when used as monotherapy and/or with OADs, with the largest percentage observed with dapagliflozin. These serious AEs are similar to those reported with metformin $(2.0 \%$ to $10.2 \%)$, metformin plus SU (8.1\% to $15.2 \%)$, metformin plus SU and sitagliptin (5.6\%), metformin plus pioglitazone $(4.3 \%)$, SU (4.8\%), pioglitazone (2.9\%), metformin plus sitagliptin $(35.2 \%)$, and insulin with or without other AHAs $(6.4 \%$ to $19.8 \%$ ). ${ }^{17,19-24,26-29,31,32,37-39,42,43,46,49,50}$ Only $0.9 \%$ to $9.9 \%$ of the 
experienced AEs with the SGLT2 inhibitors resulted in drug discontinuation, which is also similar to metformin $(0 \%$ to $6.6 \%$ ), metformin plus SU (5.8\% to $7.6 \%)$, metformin plus SU and sitagliptin (2.9\%), metformin plus pioglitazone (5.2\%), SU (2.1\%), pioglitazone (3.6\%), metformin plus sitagliptin $(0 \%)$, and insulin with or without other AHAs (2.1\% to $6.6 \%) .{ }^{17,19-24,26-29,31,32,37-39,42,43,46,49,50}$

The mechanism of action and increased amount of glucose in the urine, led to higher rates of genital mycotic infections amongst SGLT2 inhibitors, with a higher proportion in females than males $(7.4 \%$ to $25.0 \%$ and $2.5 \%$ to $8.3 \%$, respectively). ${ }^{19-26,31-46}$ These genital mycotic infections were mild to moderate in severity, generally treated with antifungal therapies prescribed by healthcare professionals or by selftreatment, and $<1 \%$ led to discontinuation of therapy. ${ }^{17,23,40,41}$ Amongst the male population in canagliflozin studies, uncircumcised males were at a higher risk of developing genital infections (eg, balanitis/balanoposthitis). ${ }^{35,36}$ Female genital mycotic infections consisted of vulvitis, vulvovaginal candidiasis, vulvovaginal mycotic infection, vulvovaginitis. ${ }^{20-22,35-43,45,46}$ There was also a higher prevalence of non-dose-dependent urinary tract infections (UTIs) (2.9\% to $13.3 \%)$ compared to placebo, which responded to standard therapies, occurred at similar rates as pioglitazone or sitagliptin, and only $<1 \%$ resulted in discontinuation of therapy. ${ }^{18,20,21,24,25,37-39,42,43}$ Both genital infection and UTI cases occurred within the first year of therapy and had low recurrence rates of $<3 \% .^{24,25}$ When looking further into the discontinuation of therapy in dapagliflozin treated patients, all discontinuations due to genital infections or UTIs occurred within the first year of therapy with no discontinuations in the second year of treatment. ${ }^{20-22}$

The mechanism of the drug class also leads to concerns about AEs associated with its osmotic diuresis effects leading to volume depletion and orthostatic hypotension; however, these remained less than $3 \%$ across all treatment arms and were mild to moderate in nature. ${ }^{37-39}$ Meanwhile, SGLT2 inhibitors have a non-insulin based mechanism, allowing for very low rates (non-dose-dependent) of hypoglycemia of $0.9 \%$ to $4.3 \%$ when used alone as monotherapy. ${ }^{17-19,35,48,49}$ The risk of hypoglycemia increased up to $\sim 6 \%$ when used with metformin, which is less than that seen with metformin monotherapy $(\sim 9 \%)$ and similar to that seen when adding sitagliptin to metformin $(\sim 5 \%))^{24,37-39,49}$ Rates of hypoglycemia of up to $\sim 2 \%$ resulted when added to pioglitazone and up to $\sim 5 \%$ when added to metformin and pioglitazone, which is just slightly higher than when an SGLT2 inhibitor was not added ( $\sim 1 \%$ and $\sim 3 \%$, respectively). ${ }^{27-29,45}$ Increases in hypoglycemia of up to $\sim 8 \%$ developed when used along with an SU and up to $\sim 43 \%$ with metformin plus SU, which was similar to those seen without the addition of an SGLT2 inhibitor ( $\sim 5 \%$ and $\sim 46 \%$, respectively) and is also similar to the rate of hypoglycemia seen with the addition of sitagliptin to metformin and an SU ( 41\%). ${ }^{20-22,26,37-43}$ Lastly, similarities in hypoglycemia were seen when SGLT2 inhibitors were added to insulin with or without other antihyperglycemic agents compared to placebo $(\sim 61 \%$ versus $\sim 62 \%$, respectively). ${ }^{31,32,46}$ Severe hypoglycemic events were even scarcer at $<1 \%$. $^{40,41}$

Overall, minor differences in laboratory values are seen with SGLT2 inhibitor use. Serum creatinine showed slight increases of $1.0 \%$ to $5.9 \%$ with commensurate decreases in eGFR of $-1.0 \%$ to $-5.1 \%$ and moderate increases in blood urea nitrogen $(\mathrm{BUN})(11.1 \%$ to $22.0 \%) .^{17,23,26,35-46}$ However, there was no evidence of deterioration of renal function with SGLT2 inhibitor use. ${ }^{26,60}$ Of the three SGLT2 inhibitors, only those studies performed with canagliflozin presented data on changes in liver function, which included moderate decreases in alanine aminotransferase (ALT) $(-3.5 \%$ to $-14.2 \%)$ and gamma-glutamyl transpeptidase (GGT) $(-3.7 \%$ and $-15.8 \%) .{ }^{35,37-43,45,46}$ Other laboratory value changes worth noting are decreases in serum uric acid of $-6.5 \%$ to $-17.8 \%$ seen in all three SGLT2 inhibitors and small increases in hemoglobin (3.6\% to $4.8 \%$ ) depicted in canagliflozin studies and hematocrit in dapagliflozin and empagliflozin studies. ${ }^{17,23,26,35,37-43,45,46}$ The small dose-dependent increases in BUN and hemoglobin/ hematocrit represent the diuretic effect of SGLT2 inhibition, with no signals for dehydration noted. ${ }^{17}$ These laboratory values returned to baseline after discontinuation of therapy. ${ }^{17}$

\section{Additional benefits beyond glucose lowering}

In addition to lowering glucose, SGLT2 inhibitors exhibit several effects that could be of benefit for patients with metabolic syndrome, such as body weight reduction, decreases in blood pressure (more systolic compared to diastolic), and positive effects on the lipid panel. ${ }^{7}$ In addition, significant decreases in serum uric acid have been reported which can possibly indicate a decrease in risk for $\mathrm{CV}$ events. ${ }^{61}$

\section{Body weight}

Body weight loss of about $-1.09 \mathrm{~kg}$ to $-5.05 \mathrm{~kg}$ has been reported across all studies with SGLT2 inhibitors and is sustained long-term as demonstrated by a 2 year study with dapagliflozin. ${ }^{19}$ Weight reduction observed with inhibition of SGLT2 differs between early-stage (patients with type 
$2 \mathrm{DM}$ not receiving treatment for their hyperglycemia) and late-stage (patients were on insulin therapy) type 2 diabetics, with greater reductions seen among late-stage (patients with type $2 \mathrm{DM}$ on high doses of insulin plus oral insulin sensitizers) $(-4.30 \mathrm{~kg}$ to $-5.05 \mathrm{~kg})$ compared to early-stage patients $(-2.00 \mathrm{~kg}$ to $-2.50 \mathrm{~kg}) .^{62}$ In addition, there is a positive correlation between baseline body weight and body weight reduction in late-stage patients, whereas this relationship was unrelated in early-stage patients. ${ }^{62}$ The influence of these differences is not clear as the caloric loss from urinary glucose did not differ between the two groups. ${ }^{62}$ However, in late-stage patients, dapagliflozin use resulted in insulin dose reduction, which was not controlled for and has a likely chance to enhance the weight reduction seen. ${ }^{62}$

The decrease in body weight observed with both canagliflozin and dapagliflozin use was predominately (approximately two-thirds) from loss of fat mass rather than lean mass. ${ }^{63-65}$ Additionally, the loss of fat was slightly more from visceral abdominal tissue than from subcutaneous abdominal tissue and had accompanying reductions in waist circumference of approximately $-1.6 \%$ to $-3.5 \%$ or approximately $-1.52 \mathrm{~cm} \cdot{ }^{17,63-65}$ SGLT2 inhibition exhibited a faster decline in total body weight over the first few weeks, followed by a more gradual decline, which never plateaued at 24 weeks of therapy with dapagliflozin. ${ }^{17,63-65}$ These reductions in body weight and waist circumference were significantly associated with an increased spot UGE which was sustained over the entire treatment duration, supporting the idea that caloric loss from glucosuria (200-300 calories per day), and not fluid loss through osmotic diuresis, is the major contributing factor to long term reduction of body weight. ${ }^{8,18,65}$ However, initially, fluid loss from the osmotic diuresis effects of the agents contributed to the faster decline in weight at initiation of therapy. ${ }^{8,17}$

Body weight reduction associated with SGLT2 inhibitor use can mitigate the weight gain accompanying pioglitazone and insulin, which was demonstrated when dapagliflozin was added to pioglitazone or insulin therapy. ${ }^{27-30}$ Initially, dapagliflozin in addition to pioglitazone resulted in slight weight reduction, but was followed by gradual weight gain toward baseline. ${ }^{27-29}$ However, the weight gain present when dapagliflozin $5 \mathrm{mg}$ or $10 \mathrm{mg}$ was added to pioglitazone was significantly lower than the weight gain that appeared with pioglitazone and placebo $(1.35 \mathrm{~kg}$ and $0.69 \mathrm{~kg}$ versus $2.99 \mathrm{~kg}) .{ }^{27-29}$ A probable explanation for the decrease in weight gain is that the diuretic effects of SGLT2 inhibitors mitigates the fluid retaining effects of pioglitazone as evidenced by fewer reports of peripheral edema compared to placebo (dapagliflozin $5 \mathrm{mg}$ and $10 \mathrm{mg}$ versus placebo: $4.3 \%$ and $2.1 \%$ versus $6.5 \%) .{ }^{27-29}$

\section{Blood pressure}

All studies with SGLT2 inhibitors to date demonstrated significant reductions in blood pressure, with greater reductions seen in systolic $(-1.66 \mathrm{mmHg}$ to $-6.9 \mathrm{mmHg})$ than diastolic $(-0.88 \mathrm{mmHg}$ to $-3.5 \mathrm{mmHg}){ }^{35,37-43,45,46,49}$ The effects on blood pressure were not dose-dependent and were not accompanied by any notable changes in heart rate or increases in hypotension and/or syncope..$^{8,17}$ A pooled analysis from Phase IIb studies with empagliflozin revealed even greater decreases in systolic blood pressure of $13.4 \mathrm{mmHg}$ to $17 \mathrm{mmHg}$ amongst a subgroup of patients with a baseline systolic blood pressure $>140 \mathrm{mmHg}$ compared to the overall population. ${ }^{66}$ This data is supported from the results of a study with dapagliflozin which also demonstrated more pronounced blood pressure effects in patients with a baseline systolic blood pressure $>140 \mathrm{mmHg}$. These reductions in systolic blood pressure were not correlated with change in body weight or glycemic control, suggesting the antihypertensive effects of empagliflozin and other SGLT2 inhibitors are independent of $\mathrm{HbA}_{1 \mathrm{c}}$ or body weight reduction. ${ }^{66}$ However, controversy around whether SGLT2 inhibitor use produced long-term reductions in blood pressure has emerged based on the results of a long-term (102 weeks) study with dapagliflozin. ${ }^{19}$ This long-term study discovered the initial blood pressure reductions seen at 24 weeks gradually returned to baseline by week 102; however, this study did not control for changes in background antihypertensive medications, a large limitation to the study results. ${ }^{19}$

The initial reduction in blood pressure seen with SGLT2 inhibitor use is believed to be due to the osmotic diuresis effects from inhibition of renal glucose and sodium reabsorption. ${ }^{67}$ Over time, this prolonged reduction in blood pressure can theoretically be attributed to local inhibition of the renin-angiotensin system (RAS). ${ }^{67}$ Inhibition of SGLT2 in the proximal convoluted tubule ultimately results in an increase in the sodium content passing through the distal convoluted tubule. ${ }^{68}$ The macula densa cells, within the distal convoluted tubule, of the juxtaglomerular apparatus sense an increase in sodium levels and inhibit the juxtaglomerular cells from releasing renin. ${ }^{68}$ This RAS inhibition can not only produce reductions in blood pressure, but can result in nephroprotection owing to the decrease in intraglomerular pressure and hyperfiltration. ${ }^{67}$ Although this mechanism of enhanced sodium excretion is slightly diminished with chronic SGLT2 inhibitor use due to tubuloglomerular feed- 
back, sodium excretion with chronic SGLT2 inhibitors in diabetics still exceeds that of diabetics without SGLT2 inhibitor use. ${ }^{69}$ Research on this concept in humans has not been performed, therefore further studies need to be completed in this area in order to validate this theory and mechanism. ${ }^{67,69}$ Nonetheless, despite the mechanism of blood pressure reduction with SGLT2 inhibitors, they are comparable to those blood pressure reductions seen with antihypertensive agents and has a favorable effect on $\mathrm{CV}$ risk. ${ }^{8}$

\section{Lipids}

Amongst various SGLT2 inhibitors there is inconsistency with their effects on the lipid profile. Overall, canagliflozin $300 \mathrm{mg}$ daily had positive effects on the lipid profile with increases in high-density lipoprotein by $7.1 \%$ to $10.6 \%$, decreases in triglyceride by $-2.3 \%$, and increases in lowdensity lipoprotein by $7.1 \%{ }^{8,35,46}$ However these changes in lipid profiles were not established with dapagliflozin use. ${ }^{70}$ After 24 weeks of therapy with dapagliflozin, no significant changes in the lipid profile were noted besides small increases in high-density lipoprotein. ${ }^{18}$

\section{Uric acid reduction}

Serum uric acid levels were consistently decreased amongst SGLT2 inhibitors, ranging from $-5.9 \%$ to $-17.8 \%$ when used as monotherapy or with OADs, and were sustained over entire treatment durations up to 102 weeks. ${ }^{71}$ However, when used in combination with insulin, the decline in uric acid levels was diminished to about $-3.86 \%$ to $-4.9 \%$ possibly related to the hyperuricemic effects of hyperinsulinism. ${ }^{36,71}$ Decreases in serum uric acid by SGLT2 inhibitors might be of importance given mounting evidence of the relationship between uric acid levels and CV disease., 3 The exact mechanism by which SGLT2 inhibition and uric acid reduction are related is unknown, but may involve a direct effect on renal uric acid transport or an indirect effect secondary to corresponding decreases in sodium reabsorption in the proximal tubule. ${ }^{71,72}$ Serum concentration of uric acid parallels sodium absorption by the kidney, therefore when SGLT2 inhibitors inhibit both sodium and glucose reabsorption, the outcome is excretion of uric acid. ${ }^{72}$ Further research is needed to ascertain the clinical significance of modest lowering of serum uric acid in patients with type 2 diabetes. $^{71}$

\section{Special populations}

\section{Renal impairment}

Kidney disease is a common complication for type 2 DM and the use of many AHAs is limited in patients with renal impairment due to their clearance through the kidney. ${ }^{39}$
With SGLT2 inhibitors, the rate of UGE is dependent on renal function (glomerular filtration rate) because as glucose filtration decreases, so does the amount of glucose available for SGLT2 inhibition. ${ }^{73}$ Therefore, the effects of SGLT2 inhibitors are expected to diminish with moderate renal impairment and reduced glomerular filtration rate. ${ }^{39}$ After 26 weeks of therapy, in patients with moderate renal impairment (eGFR $\geq 30$ and $<50 \mathrm{~mL} /$ minute) $\mathrm{HbA}_{1 \mathrm{c}}$ was reduced significantly more with canagliflozin $100 \mathrm{mg}$ or $300 \mathrm{mg}$ daily compared to placebo $(-0.33 \%$ to $-0.44 \%$ versus $-0.03 \%) .{ }^{74-76}$ However, the reduction in $\mathrm{HbA}_{1 \mathrm{c}}$ is diminished in patients with an eGFR $<45 \mathrm{~mL} /$ minute compared to those with an eGFR $\geq 45 \mathrm{~mL} /$ minute. $^{77}$

In patients with moderate renal impairment already present, canagliflozin was associated with transient decreases in renal function that attenuated over the study period and there was no evidence of renal injury as demonstrated by decreases in the urine albumin-to-creatinine ratio compared to placebo ( $-96.2 \mathrm{mg} / \mathrm{g}$ to $-117.5 \mathrm{mg} / \mathrm{g}$ versus $15.4 \mathrm{mg} / \mathrm{g}) .^{74}$ The same effects on renal function occurred with dapagliflozin use in patients with moderate renal impairment; dose-dependent decreases in eGFR occurred at week 1 of therapy (with no increases in AEs), but then stabilized versus a continued gradual decline in renal function in placebo patients. ${ }^{78,79}$

Renal clearance of dapagliflozin and modest accumulation of dapagliflozin $(<40 \%)$ from the first dose to steady state was correlated with the degree of renal impairment in patients with mild, moderate, and severe renal impairment. ${ }^{73}$ However, this increase in dapagliflozin exposure did not result in correspondingly higher urinary renal glucose clearance.$^{80}$ Comparable amounts of glucose were excreted by type $2 \mathrm{DM}$ patients with normal renal function and those with mild renal impairment (eGFR 50-80 mL/minute) suggesting that the efficacy of dapagliflozin is not diminished with mild renal impairment. ${ }^{73}$ However, in patients with moderate (eGFR 30-50 $\mathrm{mL} /$ minute) or severe (eGFR 10-30 mL/minute) renal impairment, UGE was substantially less than those with normal renal function or mild renal impairment. ${ }^{73}$ Specifically in patients with moderate renal impairment, UGE with dapagliflozin was about half of that seen in patients with normal renal function and dapagliflozin use did not significantly improve glycemic measures such as $\mathrm{HbA}_{1 \mathrm{c}}$ or FPG. ${ }^{78}$

\section{Bone and elderly}

Patients with type 2 DM have an increased risk of bone fractures, due to unclear reasons, which can be amplified by some OADs on the market, such as thiazolidinediones. ${ }^{81}$ 
Therefore, it is important to assess the effects of SGLT2 inhibitors on bone structure and function. Relative to placebo, treatment with canagliflozin resulted in increases in bone resorption markers, beta-CTx $(17.1 \%$ to $24.9 \%)$ and small decreases in the bone formation marker, procollagen type $1 \mathrm{~N}$-terminal propeptide (P1 NP) $(-5.7 \%$ to $-6.9 \%)$, which was also found with dapagliflozin use in the general population. ${ }^{29,82}$ These changes in bone markers are similar to those changes seen with pioglitazone use, which resulted in increases in beta-CTx of $16.8 \%$ without decreases in P1 NP. ${ }^{81}$ However, although SGLT2 inhibitor data indicates changes in bone resorption and formation markers, there is no increase in the incidence of fracture compared to placebo. ${ }^{82}$ Dual-energy $\mathrm{X}$-ray absorptiometry (DEXA) results with canagliflozin use showed minimal changes in bone mineral density (BMD) at the lumbar spine, distal forearm, femoral neck, and total hip, which is a benefit compared to pioglitazone, which is known to have an increased risk of fractures of $5.1 \%$ compared to a risk of $2.5 \%$ in those treated with placebo therapy. ${ }^{82,83}$

In patients of all ages, dapagliflozin resulted in similar reductions in $\mathrm{HbA}_{1 \mathrm{c}}$, as well as similar safety profiles, except for higher incidences of related AEs, discontinuations, and events of renal impairment. ${ }^{84}$ When dapagliflozin was added to standard of care therapy over 24 weeks in elderly patients with comorbid $\mathrm{CV}$ disease and hypertension, there was no impact on CV safety. ${ }^{84}$ In patients 55 to 80 years of age on a variety of background $\mathrm{OADs}$, similar $\mathrm{HbA}_{1 \mathrm{c}}$ reductions $(-0.60 \%$ to $-0.73 \%)$ were seen in those studies in patients of all ages with a similar safety profile. ${ }^{82}$

\section{Conclusion}

In summary, SGLT2 inhibition is emerging as a common sense, yet elegant mechanism for slowing the assault of diabetes on patients who have been treated with conventional agents. Several agents with similar profiles are racing to market, reminiscent of the sprint undertaken by the dipeptidyl peptidase-4 inhibitors. These drugs appear to have similar benefits and risk within the class, which include meaningful reductions on $\mathrm{HbA}_{1 \mathrm{c}}$ and $\mathrm{FPG}$ and an increase in the risk for certain types of infections. Most intriguing perhaps is their ability to positively influence other important metrics, including body weight, blood pressure, lipids, and uric acid. Older agents have typically been riddled with unfavorable effects on body weight (SU, TZDs, insulin), the CV system (SU and TZDs), and lipids (TZDs). Given that most patients exhibit multiple metabolic aberrations, the multimodal profile of SGLT2 inhibitors is certainly refreshing. There are still unanswered questions around the possible risk for cancer, the durability of these agents, and how their favorable metabolic profiles will influence the risk for microvascular and macrovascular disease.

\section{Disclosure}

The authors declare no conflicts of interest in this work.

\section{References}

1. Centers for Disease Control and Prevention. National Diabetes Fact Sheet: National Estimates and General Information on Diabetes and Prediabetes in the United States, 2011. Atlanta, GA: US Department of Health and Human Services, Centers for Disease Control and Prevention; 2011. Available from: http://www.cdc.gov/diabetes/pubs/ pdf/ndfs_2011.pdf. Accessed December 27, 2012.

2. Centers for Disease Control and Prevention. Diabetes Report Card 2012. Atlanta, GA: Centers for Disease Control and Prevention, US Department of Health and Human Services; 2012. Available from: http:// www.cdc.gov/diabetes/pubs/pdf/DiabetesReportCard.pdf. Accessed December 27, 2012.

3. Basile J. A new approach to glucose control in type 2 diabetes: the role of kidney sodium-glucose co-transporter 2 inhibition. Postgrad Med. 2011;123(4):38-45.

4. Kruger DF, Bode B, Spollett GR. Understanding GLP-1 analogs and enhancing patients success. Diabetes Educ. 2010;36 Suppl 3: 44S-72S.

5. Stark Casagrande S, Fradkin JE, Saydah SH, Rust KF, Cowie CC. The Prevalence of Meeting A1C, Blood Pressure, and LDL Goals Among People With Diabetes, 1988-2010. Diabetes Care. Epub February 15, 2013.

6. Marsenic O. Glucose control by the kidney: an emerging target in diabetes. Am J Kidney Dis. 2009;53(5):875-883.

7. Idris I, Donnelly R. Sodium-glucose co-transporter-2 inhibitors: an emerging new class of oral antidiabetic drug. Diabetes Obes Metab. 2009;11(2):79-88.

8. Foote C, Perkovic V, Neal B. Effects of SGLT2 inhibitors on cardiovascular outcomes. Diab Vasc Dis Res. 2012;9(2):117-123.

9. Vallaeys L, Van Biervliet S, De Bruyn G, et al. Congenital glucosegalactose malabsorption: a novel deletion within the SLC5A1 gene. Eur J Pediatr. 2013;172(3):409-411.

10. Francis J, Geller D. Glucosuria, Primary Renal. In: Florian Lang, editor. Encyclopedia of Molecular Mechanisms of Disease. New York: Springer-Verlag GmbH Berlin Heidelberg; 2009:719-721.

11. Canagliflozin [package insert]. Titusville, NJ: Janssen Pharmaceuticals, Inc; 2013.

12. Song J. Dapagliflozin: An emerging treatment option for type 2 diabetes mellitus. Formulary [serial on the Internet]. Oct 2011;46:412-431. $\mathrm{http}$ //formularyjournal.modernmedicine.com/formulary-journal/news/ clinical/clinical-pharmacology/dapagliflozin-emerging-treatmentoption-type-2. Accessed May 21, 2013.

13. Burki T. FDA rejects novel diabetes drug over safety fears. Lancet. 2012;379(9815):507.

14. Ptaszynska A, Johnsson K, Apanovitch A, Sugg J, Parikh S, List J. Safety of Dapagliflozin in Clinical Trials for T2DM. Presented at 72nd American Diabetes Association Scientific Sessions; June 8-12, 2012; Philadelphia, PA, USA.

15. Leiter L, Cefalu W, de Bruin T, Gause-Nilsson I, Sugg J, Parikh S. Efficacy and Safety of Dapagliflozin for Type 2 Diabetes Mellitus Patients with a History of Cardiovascular Disease. Presented at 72nd American Diabetes Association Scientific Sessions; June 8-12, 2012; Philadelphia, PA, USA.

16. Dapagliflozin [summary of product characteristics]. Middlesex, United Kingdom: Bristol-Myers Squibb/AstraZeneca; 2013.

17. List JF, Woo V, Morales E, Tang W, Fiedorek FT. Sodium-glucose cotransport inhibition with dapagliflozin in type 2 diabetes. Diabetes Care. 2009;32(4):650-657. 
18. Ferrannini E, Ramos SJ, Salsali A, Tang W, List JF. Dapagliflozin monotherapy in type 2 diabetic patients with inadequate glycemic control by diet and exercise: a randomized, double-blind, placebo-controlled, phase 3 trial. Diabetes Care. 2010;33(10): 2217-2224.

19. Woo V, Tang W, Salsali A, List J. Long-term Efficacy of Dapagliflozin Monotherapy in Patients with Type 2 Diabetes Mellitus. Presented at IDF World Diabetes Congress; December 4-8, 2011; Dubai, United Arab Emirates.

20. Nauck M, Del Prato S, Rohwedder K, Theuerkauf A, Langkilde A, Parikh S. Long-tern Efficacy and Safety of Dapagliflozin vs Glipizide Added to Metformin in Patients with Inadequately Controlled T2DM. Presented at 4th World Congress on Controversies in Diabetes, Obesity, and Hypertension (CODHy); November 8-11, 2012; Barcelona, Spain.

21. Nauck M, Del Prato S, Rohwedder K, Theuerkauf A, Langkilde A, Parikh S. Long-term Efficacy and Safety of Add-on Dapagliflozin vs Add-on Glipizide in Patients with T2DM Inadequately Controlled with Metformin: 2-year Results. Presented at 71st American Diabetes Association Scientific Sessions; June 24-28, 2011; San Diego, CA, USA.

22. Del Prato S, Nauck M, Rohwedder K, Theuerkauf A, Langkilde A, Parikh S. Long-term Efficacy and Safety of Add-on Dapagliflozin vs Add-on Glipizide in Patients with T2DM Inadequately Controlled with Metformin: 2-year Results. Presented at 47th EASD Annual Meeting; September 12-16, 2011; Lisbon, Portugal.

23. Nauck MA, Del Prato S, Meier JJ, et al. Dapagliflozin versus glipizide as add-on therapy in patients with type 2 diabetes who have inadequate glycemic control with metformin: a randomized, 52-week, double-blind, activecontrolled noninferiority trial. Diabetes Care. 2011;34(9): 2015-2022.

24. Bailey C, Gross J, Hennicken D, Iqbal N, Mansfield T, List J. Longterm Efficacy of Dapagliflozin as Add-on to Metformin in T2DM Inadequately Controlled with Metformin Alone. Presented at 71st American Diabetes Association Scientific Sessions; June 24-28, 2011; San Diego, CA, USA.

25. Bailey C, Gross J, Hennicken D, Iqbal N, Mansfield T, List J. Longterm Efficacy of Dapagliflozin as Add-on to Metformin in T2DM Inadequately Controlled with Metformin Alone. Presented at 4th World Congress on Controversies in Diabetes, Obesity, and Hypertension (CODHy); November 8-11, 2012; Barcelona, Spain.

26. Strojek K, Yoon KH, Hruba V, Elze M, Langkilde AM, Parikh S. Effect of dapagliflozin in patients with type 2 diabetes who have inadequate glycaemic control with glimepiride: a randomized, 24-week, double-blind, placebo-controlled trial. Diabetes Obes Metab. 2011;13(10):928-938.

27. Rosenstock J, Vico M, Wei L, Salsali A, List J. Dapagliflozin AddedOn to Pioglitazone Reduces HbA1c and Mitigates Weight Gain with low Incidence of Hypoglycemia in Type 2 Diabetes. Presented at 71st American Diabetes Association Scientific Sessions; June 24-28, 2011; San Diego, CA, USA.

28. Vico M, Wei L, Salsali A, List J, Rosenstock J. Dapagliflozin Addedon to Pioglitazone is Effective in Improving Glycaemic Control and Attenuates Weight Gain Without Increasing Hypoglycemia in Patients with Type 2 Diabetes. Presented at 47th EASD Annual Meeting; September 12-16, 2011; Lisbon, Portugal.

29. Rosenstock J, Vico M, Wei L, Salsali A, List JF. Effects of dapagliflozin, an SGLT2 inhibitor, on $\mathrm{HbA}(1 \mathrm{c})$, body weight, and hypoglycemia risk in patients with type 2 diabetes inadequately controlled on pioglitazone monotherapy. Diabetes Care. 2012;35(7):1473-1478.

30. Wilding J, Woo V, Soler N, et al. Long-term efficacy of dapagliflozin in patients with type 2 diabetes mellitus receiving high doses of insulin: a randomized trial. Ann Intern Med. 2012;156(6): $405-415$

31. Woo V, Wilding J, Rohwedder K, Sugg J, Parikh S. Long-term Effectiveness of Dapagliflozin Over 104 Weeks in Patients with T2DM Inadequately Controlled with Insulin. Presented at 4th World Congress on Controversies in Diabetes, Obesity, and Hypertension (CODHy); November 8-11, 2012; Barcelona, Spain.
32. Wilding J, Woo V, Rohwedder K, Sugg J, Parikh S. Long-Term Effectiveness of Dapagliflozin Over 104 Weeks in Patients with Type 2 Diabetes Poorly Controlled with Insulin. Presented at 72nd American Diabetes Association Scientific Sessions; June 8-12, 2012; Philadelphia, PA, USA.

33. FDA.gov [homepage on the Internet]. Silver Spring, MD: US Food and Drug Administration. Available from: http:/www.fda.gov/NewsEvents/ Newsroom/PressAnnouncements/ucm345848.htm. Accessed May 21, 2013.

34. Jnj.com [homepage on the Internet]. Raritan, NJ: Johnson and Johnson; Available from: http://www.jnj.com/connect/news/all/fda-advisorycommittee-recommends-approval-of-canagliflozin-for-treatment-ofadults-with-type-2-diabetes. Accessed May 21, 2013.

35. Stenlof K, Cefalu W, Tong C, et al. Canagliflozin, a sodium glucose co-transporter 2 inhibitor, improves glycaemic control in subjects with type 2 diabetes inadequately controlled with diet and exercise. Presented at 48th EASD Annual Meeting; October 1-5, 2012; Berlin, Germany.

36. Polidori D, Law G, Alba M, Ferrannini E. Treatment with Canagliflozin, a Sodium Glucose Co-Transporter 2 Inhibitor, for 26 Weeks Improves Indices of Beta-cell Function. Presented at 72nd American Diabetes Association Scientific Sessions; June 8-12, 2012; Philadelphia, PA, USA.

37. Cefalu W, Leiter L, Niskanen L, et al. Efficacy and Safety of Canagliflozin, a Sodium Glucose Co-Transporter 2 Inhibitor, Compared With Glimepiride in Patients with Type 2 Diabetes on Background Metformin. Presented at 72nd American Diabetes Association Scientific Sessions; June 8-12, 2012; Philadelphia, PA, USA.

38. Niskanen L, Cefalu W, Leiter L, et al. Efficacy and safety of canagliflozin, a sodium glucose co-transporter 2 inhibitor, compared with glimepiride in patients with type 2 diabetes on background metformin. Presented at 48th EASD Annual Meeting; October 1-5, 2012; Berlin, Germany.

39. Niskanen L, Cefalu W, Leiter L, et al. Efficacy and safety of canagliflozin, a sodium glucose co-transporter 2 inhibitor, compared with glimepiride in patients with type 2 diabetes on background metformin. Presented at 4th World Congress on Controversies in Diabetes, Obesity, and Hypertension (CODHy); November 8-11, 2012; Barcelona, Spain.

40. Wilding J, Mathieu C, Vercruysse F, et al. Canagliflozin, a sodium glucose co-transporter 2 inhibitor, improves glycaemia in subjects with type 2 diabetes inadequately controlled with metformin plus sulphonylurea. Presented at 72nd American Diabetes Association Scientific Sessions; June 8-12, 2012; Philadelphia, PA, USA.

41. Wilding J, Mathieu C, Deng L, et al. Canagliflozin, a sodium glucose co-transporter 2 inhibitor, improves glycaemia in subjects with type 2 diabetes inadequately controlled with metformin plus sulphonylurea. Presented at 48th EASD Annual Meeting; October 1-5, 20125; Berlin, Germany.

42. Gross J, Schernthaner G, Fu M, et al. Efficacy and Safety of Canagliflozin, a Sodium Glucose Co-Transporter 2 Inhibitor, Compared with Sitagliptin in Patients with Type 2 Diabetes On Metformin Plus Sulfonylurea. Presented at 72nd American Diabetes Association Scientific Sessions; June 8-12, 2012; Philadelphia, PA, USA.

43. Schernthaner G, Gross J, Fu M, et al. Efficacy and safety of canagliflozin, a sodium glucose co-transporter 2 inhibitor, compared with sitagliptin in patients with type 2 diabetes on metformin plus sulphonylurea. Presented at 4th World Congress on Controversies in Diabetes, Obesity, and Hypertension (CODHy); November 8-11, 2012; Barcelona, Spain.

44. Polidori D, Vercruysse F, Ferrannini E. Canagliflozin, a sodium glucose co-transporter 2 (SGLT2) inhibitor, improves indices of beta cell function in patients with type 2 diabetes on metformin plus sulphonylurea. Presented at 48th EASD Annual Meeting; October 1-5, 2012; Berlin, Germany.

45. Forst T, Guthrie R, Goldenberg R, et al. Efficacy and Safety of Canagliflozin in Subjects with Type 2 Diabetes on Metformin and Pioglitazone. Presented at 4th World Congress on Controversies in Diabetes, Obesity, and Hypertension (CODHy); November 8-11, 2012; Barcelona, Spain. 
46. Matthews D, Fulcher G, Perkovic V, et al. Efficacy and safety of canagliflozin (CANA), an inhibitor of sodium glucose co-transporter 2 (SGLT2), added-on to insulin therapy with or without oral agents in type 2 diabetes. Presented at 48th EASD Annual Meeting; October 1-5, 2012; Berlin, Germany.

47. Newsroom.lilly.com [homepage on the Internet]. Indianapolis, IN: Eli Lilly and Company; Boehringer Ingelheim. Available from: http:// newsroom.lilly.com/releasedetail.cfm?releaseid=731715. Accessed May 21, 2013.

48. Ferrannini E, Seman L, Seewaldt-Becker E, Hantel S, Pinnetti S, Worle H. The Potent and Highly Selective Sodium Glucose Cotransporter-2 (SGLT2) Inhibitor BI 10773 is Safe and Efficacious in Patients with Type 2 Diabetes Mellitus (T2DM). Presented at 46th EASD Annual Meeting; September 20-24, 2010; Stockholm, Sweden.

49. Woerle H, Ferrannini E, Berk A, Hantel S, Pinnetti S, Broedl U. Safety and Efficacy of Empagliflozin as Monotherapy or Add-On to Metformin in a 78-Week Open-Label Extension Study in Patients with Type 2 Diabetes. Presented at 72nd American Diabetes Association Scientific Sessions; June 8-12, 2012; Philadelphia, PA, USA.

50. Rosenstock J, Jelaska A, Seman L, Pinnetti S, Hantel S, Woerle H. Efficacy and Safety of BI 10773 (Empagliflozin), a New Sodium Glucose Cotransporter-2 (SGLT-2) Inhibitor, in Type 2 Diabetes Inadequately Controlled on Metformin. Presented at 71st American Diabetes Association Scientific Sessions; June 24-28, 2011; San Diego, CA, USA.

51. Kurosaki E, Ogasawara H. Ipragliflozin and other sodium-glucose cotransporter-2 (SGLT2) inhibitors in the treatment of type 2 diabetes: Preclinical and clinical data. Pharmacol Ther. Jul 2013;139(1):51-59.

52. Kashiwagi A, Shiga T, Akiyama N, et al. Ipragliflozin reduced HbA1c and body weight in Japanese type 2 diabetes patients who have inadequate glycaemic control on sulfonylurea or pioglitazone alone. Presented at 48th EASD Annual Meeting; October 1-5, 2012; Berlin, Germany.

53. Freiman J, Ye G, Ogbaa I, et al. LX4211, a dual SGLT1/SGLT2 inhibitor shows a favourable gastrointestinal and genitourinary safety profile in type 2 diabetes mellitus patients and healthy subjects. Presented at 48th EASD Annual Meeting; October 1-5, 2012; Berlin, Germany.

54. Lexicon-genetics.com [homepage on the Internet]. The Woodlands, TX: Lexicon Pharmaceuticals. Available from: http://www.lexicon-genetics. com/pipeline/lx4211.html. Accessed May 21, 2013.

55. Chugai-pharm.com [homepage on the Internet]. Chuo-ku, Tokyo: Chugai Pharma USA. Available from: http://www.chugai-pharm.co.jp/ hc/ss/english/ir/reports_downloads/pipeline.html. Accessed May 21, 2013.

56. Ikeda S, Takano Y, Cynshi O, et al. A novel and selective SGLT2 inhibitor, tofogliflozin improves glycaemic control and lowers body weight in patients with type 2 diabetes mellitus. Presented at 48th EASD Annual Meeting; October 1-5, 2012; Berlin, Germany.

57. Taisho-holdings.co.jp/en [homepage on the Internet]. Toshima-ku, Tokyo: Taisho Pharmaceutical. Available from: http://www.taisho-holdings.co.jp/ en/release/2012/2012113001-e.pdf. Accessed May 21, 2013.

58. Pfizer.newshq.businesswire.com [homepage on the Internet]. New York, NY: Pfizer. Available from: http://pfizer.newshq.businesswire.com/ press-release/merck-co-inc-and-pfizer-enter-worldwide-collaborationagreement-develop-and-commercial. Accessed May 21, 2013.

59. Chao EC, Henry RR. SGLT2 inhibition-a novel strategy for diabetes treatment. Nat Rev Drug Discov. Jul 2010;9(7):551-559.

60. Bailey C, Iqbal N, T'joen C, List J. Dapagliflozin monotherapy in drugnaïve patients with diabetes: a randomized-controlled trial of low-dose range. Diabetes Obes Metab. 2012;14(10):951-959.

61. Kanbay M, Segal M, Afsar B, Kang DH, Rodriguez-Iturbe B, Johnson RJ. The role of uric acid in the pathogenesis of human cardiovascular disease. Heart. 2013;99(11):759-766.

62. Zhang L, Feng Y, List J, Kasichayanula S, Pfister M. Dapagliflozin treatment in patients with different stages of type 2 diabetes mellitus: effects on glycaemic control and body weight. Diabetes Obes Metab. 2010;12(6):510-516.
63. Toubro S, Cefalu W, Xie J, et al. Canagliflozin, a sodium glucose cotransporter 2 inhibitor, reduces body weight mainly through loss of fat mass in subjects with type 2 diabetes. Presented at 48th EASD Annual Meeting; October 1-5, 2012; Berlin, Germany.

64. Toubro S, Cefalu W, Xie J, et al. Canagliflozin reduces body weight mainly through loss of fat mass in subjects with type 2 diabetes. Presented at 4th World Congress on Controversies in Diabetes, Obesity, and Hypertension (CODHy); November 8-11, 2012; Barcelona, Spain.

65. Bolinder J, Ljunggren O, Kullberg J, et al. Effects of dapagliflozin on body weight, total fat mass, and regional adipose tissue distribution in patients with type 2 diabetes mellitus with inadequate glycemic control on metformin. J Clin Endocrinol Metab. 2012;97(3):1020-1031.

66. Hach T, Lambers Heerspink H, Pfarr E, Lund S, Ley L, Broedl U. The Sodium Glucose Cotransporter 2 (SGLT2) Inhibitor Empagliflozin Lowers Blood Pressure Independent of Weight or HbA1c Changes [poster 65]. Proceedings of the 4th World Congress on Controversies in Diabetes, Obesity, and Hypertension (CODHy); November 8-11, 2012; Barcelona, Spain.

67. Abdul-Ghani MA, Norton L, DeFronzo RA. Efficacy and safety of SGLT2 inhibitors in the treatment of type 2 diabetes mellitus. Curr Diab Rep. 2012;12(3):230-238.

68. Damkjær M, Isaksson GL, Stubbe J, Jensen BL, Assersen K, Bie P. Renal renin secretion as regulator of body fluid homeostasis. Pflugers Arch. 2013;465(1):153-165.

69. Thomson S, Rieg T, Miracle C, et al. Acute and chronic effects of SGLT2 blockade on glomerular and tubular function in the early diabetic rat. Am J Physiol Regul Integr Comp Physiol. 2012;302(1): R75-R83.

70. Woo V, Hardy E, Ptaszynska A, Parikh S. Effects of the SGLT2 Inhibitor Dapagliflozin Beyond Glucose Reduction in Patients with Type 2 Diabetes mellitus. Presented at 4th World Congress on Controversies in Diabetes, Obesity, and Hypertension (CODHy); November 8-11, 2012; Barcelona, Spain.

71. Hardy E, Rohwedder K, Hruba V, et al. Dapagliflozin, an AGLT2 Inhibitor, reduces Serum Levels of Uric Acid in patients with Type 2 Diabetes. Presented at 71st American Diabetes Association Scientific Sessions; June 24-28, 2011; San Diego, CA, USA.

72. Mount DB, Kwon CY, Zandi-Nejad K. Renal urate transport. Rheum Dis Clin North Am. 2006;32(2):313-331, vi.

73. Kasichayanula S, Liu X, Pe Benito M, et al. The influence of kidney function on dapagliflozin exposure, metabolism, and efficacy in healthy subjects and in patients with type 2 diabetes mellitus. Br J Clin Pharmacol. Epub December 4, 2012.

74. Yale JF, Bakris G, Xi L, Figueroa K, Wajs E, Usiskin K, et al. Canagliflozin (CANA), a Sodium Glucose Co-Transporter 2 (SGLT2) Inhibitor, Improves Glycemia and is Well Tolerated in Type 2 Diabetes Mellitus (T2DM) Subjects With Moderate Renal Impairment. Presented at 72nd American Diabetes Association Scientific Sessions; June 8-12, 2012; Philadelphia, PA, USA.

75. Bakris G, Yale JF, Xi L, et al. Efficacy and Safety of Canagliflozin (CANA) in Subjects with Type 2 Diabetes Mellitus (T2DM) and Moderate Renal Impairment. Presented at ASN Kidney Week; October 30-November 4, 2012; San Diego, CA, USA.

76. Yale JF, Bakris G, Wajs E, et al. Canagliflozin, a sodium glucose co-transporter 2 inhibitor, improves glycaemic control and is well tolerated in type 2 diabetes subjects with moderate renal impairment. Presented at 48th EASD Annual Meeting; October 1-5, 2012; Berlin, Germany.

77. Woo V, Davies M, de Zeeuw D, et al. Efficacy and Safety of Canagliflozin in Subjects with Type 2 Diabetes Mellitus and Moderate Renal Impairment. Presented at 4th World Congress on Controversies in Diabetes, Obesity, and Hypertension (CODHy); November 8-11, 2012; Barcelona, Spain.

78. Kohan D, Fioretto P, List J, Tang W. Efficacy and Safety of Dapagliflozin in Patients with Type 2 Diabetes and Moderate Renal Impairment. Presented at ASN Kidney Week; November 10-13, 2011; Philadelphia, PA, USA. 
79. Ptaszynska A, Chalamandaris AG, Sugg J, Johnsson K, Parikh S, List J. Effect of Dapagliflozin on Renal Function [poster 1098-P]. Proceedings of the 72nd American Diabetes Association Scientific Sessions; June 8-12, 2012; Philadelphia, PA, USA.

80. Kasichayanula S, Liu X, Pe Benito M, LaCreta F, Boulton D. Influence of Renal Function on Dapagliflozin Pharmacodynamics in Patients with Type 2 Diabetes Mellitus. Presented at ASN Kidney Week; November 10-13, 2011; Philadelphia, PA, USA.

81. van Lierop AH, Hamdy NA, van der Meer RW, et al. Distinct effects of pioglitazone and metformin on circulating sclerostin and biochemical markers of bone turnover in men with type 2 diabetes mellitus. Eur $J$ Endocrinol. 2012;166(4):711-716.

82. Bode B, Stenlof K, Sullivan D, Fung A, Usiskin K, Meininger G. Efficacy and safety of canagliflozin (CANA), a sodium glucose cotransporter 2 inhibitor (SGLT2), in older subjects with type 2 diabetes mellitus. Presented at 48th EASD Annual Meeting; October 1-5, 2012; Berlin, Germany.
83. Dormandy J, Bhattacharya M, van Troostenburg de Bruyn AR; PROactive investigators. Safety and tolerability of pioglitazone in highrisk patients with type 2 diabetes: an overview of data from PROactive. Drug Saf. 2009;32(3):187-202.

84. Cefalu W, Leiter L, de Bruin T, Gause-Nilsson I, Sugg J, Parikh S. Dapagliflozin Treatment for Type 2 Diabetes Mellitus patietns with Comorbid Cardiovascular Disease and Hypertension. Presented at 72nd American Diabetes Association Scientific Sessions; June 8-12, 2012; Philadelphia, PA, USA.

\section{Publish your work in this journal}

Diabetes, Metabolic Syndrome and Obesity: Targets and Therapy is an international, peer-reviewed open-access journal committed to the rapid publication of the latest laboratory and clinical findings in the fields of diabetes, metabolic syndrome and obesity research. Original research, review, case reports, hypothesis formation, expert opinion and commentaries are all considered for publication. The manuscript management system is completely online and includes a very quick and fair peer-review system, which is all easy to use. Visit http://www.dovepress.com/testimonials.php to read real quotes from published authors.

Submit your manuscript here: http://www.dovepress.com/diabetes-metabolic-syndrome-and-obesity-targets-and-therapy-journal 